\title{
Neuroadaptations in the Dentate Gyrus Following Contextual Cued Reinstatement of Methamphetamine Seeking
}

\author{
Yoshio Takashima ${ }^{1,2}$, McKenzie J. Fannon ${ }^{3}$, Melissa H. Galinato ${ }^{1,3}$, Noah L. Steiner ${ }^{3}$, \\ Michelle An ${ }^{3}$, Alice E. Zemljic-Harpf ${ }^{2,3}$, Sucharita S. Somkuwar ${ }^{3}$, Brian P. Head ${ }^{2,3}$, and \\ Chitra D. Mandyam ${ }^{1,2,3}$ \\ ${ }^{1}$ Department of Neuroscience, University of California San Diego \\ ${ }^{2}$ Department of Anesthesiology, University of California San Diego \\ ${ }^{3}$ VA San Diego Healthcare System, San Diego, CA, USA
}

\section{Abstract}

\begin{abstract}
Abstinence from unregulated methamphetamine self-administration increases hippocampal dependent, context-driven reinstatement of methamphetamine seeking. The current study tested the hypothesis that alterations in the functional properties of granule cell neurons (GCNs) in the dentate gyrus (DG) of the hippocampus in concert with altered expression of synaptic plasticityrelated proteins and ultrastructural changes in the DG are associated with enhanced context-driven methamphetamine-seeking behavior. Whole-cell patch-clamp recordings were performed in acute brain slices from methamphetamine naïve (controls) and methamphetamine experienced animals (during acute withdrawal, during abstinence, after extinction and after reinstatement).
\end{abstract}

\begin{abstract}
Spontaneous excitatory postsynaptic currents (sEPSCs) and intrinsic excitability were recorded from GCNs. Reinstatement of methamphetamine seeking increased sEPSC frequency and produced larger amplitude responses in GCNs compared to controls and all other groups. Reinstatement of methamphetamine seeking reduced spiking capability in GCNs compared to controls, and all other groups, as indicated by reduced intrinsic spiking elicited by increasing current injections, membrane resistance and fast afterhyperpolarization. In rats that reinstated methamphetamine seeking, these altered electrophysiological properties of GCNs were associated with enhanced expression of Fos, GluN2A subunits and PSD95 and reduced expression of $\mathrm{GABA}_{\mathrm{A}}$ subunits in the DG and enhanced expression of synaptic PSD in the molecular layer. The alterations in functional properties of GCNs and plasticity related proteins in the DG paralleled with no changes in structure of microglial cells in the DG. Taken together, our results demonstrate that enhanced reinstatement of methamphetamine seeking results in alterations in intrinsic spiking and spontaneous glutamatergic synaptic transmission in the GCNs and concomitant increases in neuronal activation of GCNs, and expression of GluNs and decreases in $\mathrm{GABA}_{\mathrm{A}}$ subunits that may contribute to the altered synaptic connectivity - neuronal circuitry - and activity in the hippocampus, and enhance propensity for relapse.
\end{abstract}

Correspondence: Chitra D. Mandyam, Ph.D.; cmandyam@scripps.edu.

Conflict of Interest

The authors declare no competing financial interests in relation to the work described. 


\section{Keywords}

Granule Cell Neurons; Whole-cell patch clamp recording; Fos; GluN; Electron Microscopy; microglia

\section{Introduction}

Methamphetamine abuse and eventual addiction takes severe emotional and financial tolls on society, cutting across ages, races, ethnicities, and genders, and causes significant damage to self, due to the high propensity for relapse (Thompson et al., 2004; SAMHSA, 2008; Price et al., 2011; Weber et al., 2012). Increased risk for relapse in methamphetamineaddicted subjects may be attributed to methamphetamine-induced alterations in structural and functional plasticity of hippocampal neurons, as preclinical studies show that the hippocampus assists with forming context-specific memories associated with reinstatement of drug seeking (Fuchs et al., 2005; Wells et al., 2016). Supporting these preclinical findings, human imaging studies show reduced hippocampal volume, particularly gray matter volume, and decreased hippocampal responsiveness in chronic methamphetamine users (Thompson et al., 2004; Kim et al., 2010; Schwartz et al., 2010; Daumann et al., 2011; Nakama et al., 2011; Orikabe et al., 2011; Morales et al., 2012), indicating maladaptive hippocampal network in methamphetamine-using individuals.

Neuronal network in the hippocampus is influenced by serial propagation and feedforward excitation through the 'hippocampal trisynaptic pathway' which is regarded as the fundamental characteristic of intrinsic hippocampal physiology (Andersen et al., 1971; Yeckel \& Berger, 1990). The three major subdivisions of the hippocampal formationdentate gyrus (DG), cornu ammonis (CA)1, CA3 have unidirectional connections between themselves (Swanson et al., 1978; Amaral \& Witter, 1989), with granule cell neurons of the DG projecting to the CA3 pyramidal neurons (mossy fibers) which in turn project to the CA1 pyramidal neurons (Schaffer collaterals). Excitatory perforant path fibers arising from the entorhinal cortex are the major afferents to the DG (Andersen et al., 1966a), and electrophysiological studies have demonstrated that activation of the perforant path can initiate a sequential excitation or feedforward excitation of DG, CA3 and CA1 neurons (Andersen et al., 1966b; Yeckel \& Berger, 1990). The multisynaptic transmissions through the hippocampal formation most importantly function to store, consolidate and retrieve declarative, spatial and associative long-term memory (Burgess et al., 2002; Squire et al., 2004). In this context, mechanistic studies from preclinical models show that methamphetamine exposure alters the functional plasticity of hippocampal neurons. For example, acute and systemic methamphetamine treatment reduces long-term potentiation (LTP) of CA1 pyramidal neurons through activation of D1 receptors and increases baseline excitatory synaptic transmission (Swant et al., 2010). Acute methamphetamine exposure reduces excitability of DG granule cell neurons (GCNs), whereas repeated exposure to methamphetamine increases excitability of these neurons (Criado et al., 2000). These studies demonstrate enhanced neuronal activity in the hippocampus in the CA and DG subregions during methamphetamine experience, however, it is yet to be determined whether these 
alterations in electrophysiological properties of hippocampal neurons persist into protracted abstinence from methamphetamine experience.

Emerging studies in adult rats self-administering methamphetamine under extended access conditions ( $6 \mathrm{~h}$ of drug access per day) demonstrate that methamphetamine selfadministration alters other forms of plasticity in the hippocampus. For example, methamphetamine self-administration reduces DG neurogenesis, and these effects were relative to the amount of methamphetamine consumed (Mandyam et al., 2008; Yuan et al., 2011). Reduction in neurogenesis during methamphetamine self-administration is associated with enhanced expression of brain-derived neurotrophic factor and hypo activity of the glutamatergic receptors in the DG, suggesting distinct allostatic changes in the hippocampus that may contribute to the altered synaptic activity in the DG (Galinato et al., 2015).

Abstinence from methamphetamine self-administration ( $>15 \mathrm{~d}$ days; a timeframe required for neurogenesis of preneuronal progenitor cells to become GCNs; (Zhao et al., 2006)) produces compensatory changes in DG neurogenesis (i.e., enhanced survival of progenitors born during acute withdrawal from methamphetamine self-administration), and the hypothesis is that these changes in the DG during abstinence may regulate relapse to methamphetamine seeking (Recinto et al., 2012; Galinato et al., 2017). Furthermore, abstinence from methamphetamine self-administration also produces robust and long-lasting morphological changes in CA1 neurons and GCNs (Crombag et al., 2005; Galinato et al., 2017), suggesting that these structural alterations may correlate with functional changes in CA1 neurons and GCNs. These studies suggest that abstinence from methamphetamine self-administration produces synaptic maladaptation in the hippocampus that may mediate reinstatement of methamphetamine seeking dependent on the hippocampus. Therefore, the current study tested the hypothesis that reinstatement of methamphetamine seeking after a period of protracted abstinence (a timeframe required for alterations in hippocampal neurogenesis to occur (Recinto et al., 2012; Galinato et al., 2017)) in an animal model of methamphetamine addiction is associated with altered functional plasticity of GCNs and altered expression of synaptic proteins linked to context-driven drug seeking behaviors.

\section{Materials and Methods}

\section{Animals}

Surgical and experimental procedures were carried out in strict adherence to the National Institutes of Health Guide for the Care and Use of Laboratory Animals (NIH publication number 85-23, revised 1996) and approved by the Institutional Animal Care and Use Committee of VA San Diego Healthcare System. Forty-three adult, male Long Evans rats (bread at the VA Vivarium), weighing 200-250 g at the start of the experiment, were housed two per cage in a temperature-controlled vivarium under a reverse light/dark cycle (lights off 8:00 AM-8:00 PM) and completed the study.

\section{Surgery for implanting jugular vein catheters}

Twenty-one rats underwent surgery for catheter implantation for intravenous selfadministration. Rats were anesthetized with $2-3 \%$ of isofluorane mixed in oxygen and implanted with a sterilized silastic catheter into the right jugular vein under aseptic 
conditions. The distal end of the catheter was threaded under the skin to the back of the rat and exited the skin via a metal guide cannula (Galinato et al., 2014). Post surgery care was provided with analgesics (Flunixin) and antibiotics (Cefazolin (Sobieraj et al., 2014)). Catheters were flushed daily with heparinized saline and tested for patency using methohexital sodium (Brevital; (Galinato et al., 2014)).

\section{Training and maintenance on an extended access schedule of intravenous methamphetamine self-administration}

Four to five days after surgery rats $(n=30)$ were trained to press a lever according to an fixed-ratio 1 (FR1) schedule of methamphetamine reinforcement $(0.05 \mathrm{mg} / \mathrm{kg} /$ injection of methamphetamine (generously provided by NIDA) for every correct response) in operant boxes (context A; Med Associates) under extended access conditions (6h access per day for 14 days). During daily sessions, a response on the active lever resulted in a 4 second infusion (90-100 $\mu \mathrm{l}$ of methamphetamine), followed by a 20 second time-out period to prevent overdose. Each infusion was paired for 4 seconds with white stimulus light over the active lever (conditioned stimulus [CS]). Response during the time-out or on the inactive lever was recorded but resulted in no programmed consequences. All animals were housed on a reverse cycle (lights off at $8 \mathrm{am}$ ) and were transferred from their home cages to their operant chambers between 9 and $10 \mathrm{am}$. Training on the first and second day was initiated with twothree priming (noncontingent) infusions of methamphetamine during the first ten minutes. Rats were allowed to respond for the remaining $3 \mathrm{~h}$ without any additional priming. Acquiring methamphetamine self-administration was defined as maintenance of similar number of infusions over 2 days during priming sessions. All animals acquired methamphetamine self-administration and experienced 14 sessions of extended access schedule after the priming sessions (Figure 1).

\section{Extinction}

Extinction sessions were performed in a new context (operant box context B, distinct from context A) for $1 \mathrm{~h}$ for six sessions. In this context, animals were not attached to the drug infusion apparatus, white noise was added during the entire session, a house light was turned on for the entire session, and black colored tape was pasted on the operant door. Responses on either the active or inactive lever were recorded and did not result in programmed consequences (i.e., no infusions and no conditioned stimulus presentations). Extinction was defined as reduced $(<30 \%)$ active lever pressing on days 4-6 vs. day 1 of extinction.

\section{Reinstatement}

Twenty-four hours after the final extinction session, animals underwent context-driven reinstatement in which they were placed into the methamphetamine- paired context (context A) for $1 \mathrm{~h}$, during which they were connected to the infusion apparatus to allow for a similar interaction with the spatial elements of the context as during methamphetamine selfadministration training. Lever presses were used as a measure of drug seeking, and responses on either the active or inactive lever were recorded and did not result in an infusion of fluids through the catheter or other programmed consequences (i.e., conditioned stimulus presentations). The next day, animals underwent context-plus-cue-induced reinstatement in which conditions were the same as context-induced reinstatement, and 
responses on the active lever resulted in the conditioned stimulus light presentation. One hour after the end of the session, animals were either anesthetized and brain tissue was processed for electrophysiology or euthanized by rapid decapitation for Western blotting.

\section{Slice preparation}

Slices for electrophysiology were prepared from methamphetamine naïve animals (controls; $\mathrm{n}=3$ rats; $\mathrm{n}=7-8$ cells) and methamphetamine experienced rats. Methamphetamine rats were either euthanized 16-18h after the self-administration session (Meth; $n=3$ rats; $n=8-9$ cells), during protracted abstinence (Meth $A b ; n=3$ rats; $n=13-15$ cells), $1 \mathrm{~h}$ after extinction session (Meth Ext; $n=3$ rats; $n=14-18$ cells) or $1 \mathrm{~h}$ after reinstatement session (Meth Rst; $n=3$ rats; $\mathrm{n}=6-8$ cells (Figure 1a)). Rats from each group were subjected to brief anesthesia (Ketamine/ Xylazine/Acepromazine (62.5/2.6/0.5 mg/kg i.p.; 0.8ml/150g) and perfused for 3 minutes with ice-cold, oxygenated (95\% O2/5\% CO2), modified sucrose artificial cerebrospinal fluid (ACSF) containing (in mM) $71 \mathrm{NaCl}, 2.5 \mathrm{KCl}, 3.3 \mathrm{MgSO} 4,0.5 \mathrm{CaCl} 2,1.2 \mathrm{NaH} 2 \mathrm{PO} 4,26.2$ NaHCO3, 22 glucose, 2.0 thiourea, 72.0 sucrose, 10 choline chloride, 0.5 pyruvate, $0.4 \mathrm{~L}$ ascorbic acid ( $\sim 300 \mathrm{mOsml}, \mathrm{pH} 7.4)$. The brain was rapidly dissected and $330 \mu \mathrm{m}$-thick slices containing regions of interest were cut on a vibratome (Leica VT1200). Slices were transferred to an interface chamber containing the same modified sucrose ACSF solution and incubated at $34^{\circ} \mathrm{C}$ for $30 \mathrm{~min}$. Slices were then held at room temperature $\left(23^{\circ} \mathrm{C}\right)$ on the interface chamber for at least $45 \mathrm{~min}$ before initiating recordings. Recordings were made in a submersion-type recording chamber and superfused with oxygenated $(95 \% \mathrm{O} 2 / 5 \% \mathrm{CO} 2)$ ACSF containing (in mM) $119 \mathrm{NaCl}, 2.5 \mathrm{KCl}, 4.0 \mathrm{MgCl} 2,2.5 \mathrm{CaCl} 2,1.0 \mathrm{NaH} 2 \mathrm{PO} 4,26$ $\mathrm{NaHCO}, 20$ glucose $(\sim 300 \mathrm{mOsml})$ at $23^{\circ} \mathrm{C}$ at a rate of $2-3 \mathrm{ml} / \mathrm{minute}$.

\section{Electrophysiology}

Whole-cell patch clamp recordings were obtained using Multiclamp 700B amplifiers (Molecular Devices) and data was collected using pClamp 10 software (Molecular Devices). Data was low-pass filtered at 2kHz, and digitized at 10kHz (Digidata 1440A; Molecular Devices). Voltage and current clamp recordings were made at room temperature using glasspulled patch pipettes (Warner Instruments, $\mathrm{OD}=1.50 \mathrm{~mm}, \mathrm{ID}=1.16 \mathrm{~mm}$, length $=10 \mathrm{~cm}$; 4-7 $\mathrm{M} \Omega$ ) filled with internal solution containing (in $\mathrm{mM}$ ) $150 \mathrm{~K}$-Gluconate, $1.5 \mathrm{MgCl} 2,5.0$ HEPES, 1.0 EGTA, 10 phosphocreatine, 2.0 ATP, and 0.3 GTP. GCNs in the dorsal DG were visualized and then targeted for whole- cell recording under infrared differential interference contrast videomicroscopy (Olympus BX-51 scope and Rolera XR digital camera).

Recordings were made from GCNs located in the middle or the outer third of the granule cell layer (Figure $4 \mathrm{a}-\mathrm{c}$ ). Cells that were impaled were first screened to ensure that they were healthy (stable resting potential; $n=8$ controls, $n=9$ reinstated rats). In voltage-clamp experiments the holding membrane potential was set to $-68 \mathrm{mV}$. Series and input resistances were monitored before and after recordings; data were discarded if it increased by $>10 \mathrm{M} \Omega$. In current-clamp experiments, currents were injected stepwise, in 20 pA increments. Step duration was $500 \mathrm{~ms}$.

Analysis of electrophysiological properties was made with Clampfit 10.4 software (Molecular Devices) as previously described (Yassin et al., 2010; Benedetti et al., 2013). In brief, resting potential is defined as the recorded membrane potential when cell membrane 
was initially broken into with a recording pipette for the whole-cell patch clamp configuration. Action potential (AP) characteristics are based on a single AP evoked by intracellular current injection (ranging between 60 to 180 pA, $500 \mathrm{msec}$ pulse). Peak amplitude is actual measured peak AP amplitude in mV. Spike threshold is defined as the voltage at which the second derivative of the membrane potential trajectory approaching a spike crossed a user-selected threshold of $20 \mathrm{mV} / \mathrm{ms}^{2}$. Half-width is the period measured in latency (ms) from the start of the AP to the time when the AP reached half of the peak amplitude. The amplitude of fast afterhyperpolarization (fAHP) was measured from the threshold voltage to the most negative overshoot after repolarization. The slope of the rise to threshold was obtained by a linear fit from completion of the fAHP to the threshold of the subsequent AP.

\section{Brain tissue collection for immunohistochemistry and Western blotting}

Rats were killed by rapid decapitation and the brains were isolated, and dissected along the midsagittal plane. The left hemisphere was snap frozen for Western blotting analysis and the right hemisphere was postfixed in $4 \%$ paraformaldehyde for immunohistochemistry (Somkuwar et al., 2016). For immunohistochemistry, the tissue was sliced in $40 \mu \mathrm{m}$ sections along the coronal plane on a freezing microtome. Sections were slide mounted and processed for $\mathrm{cFos}$ and ionized calcium-binding adapter molecule 1 (Iba-1) staining.

\section{Quantitative analysis of Fos labeled cells}

The following primary antibody was used for cFos immunohistochemistry (IHC): (1:1000, catalog \# sc-52, Santa Cruz Biotechnology (Recinto et al., 2012)). Sections representing -3.1 and $-4.3 \mathrm{~mm}$ from bregma were slide mounted and processed for immunohistochemistry (Mandyam et al., 2004). Fos immunoreactive cells were examined and quantified with a Zeiss AxioImager Microscope as described previously (Somkuwar et al., 2016). Immunoreactive cells were quantified in the area of the granule cell layer contoured for analysis. Data are represented as number of cells per $\mathrm{mm}^{2}$ of the granule cell layer.

\section{Western blotting}

Procedures optimized for measuring both phosphoproteins and total proteins were employed (Kim et al., 2015). Animals were euthanized via rapid decapitation under light isoflurane anesthesia (3-5\%) 1 hour after end of reinstatement session. Brains were quickly removed and flash-frozen. Brain tissue was cut at the mid-sagittal axis and the right hemisphere was processed for Western blotting. Tissue punches from dorsal hippocampus enriched in the DG (did not include CA 3 or CA1 areas) from $500 \mu \mathrm{m}$ thick sections were homogenized on ice by sonication in buffer (320 mM sucrose, $5 \mathrm{mM}$ HEPES, $1 \mathrm{mM}$ EGTA, 1mMEDTA, $1 \%$ SDS, with Protease Inhibitor Cocktail and Phosphatase Inhibitor Cocktails II and III diluted 1:100; Sigma), heated at $100{ }^{\circ} \mathrm{C}$ for five minutes, and stored at $-80{ }^{\circ} \mathrm{C}$ until determination of protein concentration by a detergent-compatible Lowry method (Bio-Rad, Hercules, CA). Samples were mixed (1:1) with a Laemmli sample buffer containing $\beta$-mercaptoethanol. Each sample containing protein from one animal was run (20 $\mu$ g per lane) on $8 \%$ SDSPAGE gels (Bio-Rad) and transferred to polyvinylidene fluoride membranes (PVDF pore size $0.2 \mu \mathrm{m}$ ). Blots were blocked with $2.5 \%$ bovine serum albumin (for phosphoproteins) or 
$5 \%$ milk (w/v) in TBST ( $25 \mathrm{mM}$ Tris- $\mathrm{HCl}(\mathrm{pH} 7.4), 150 \mathrm{mM} \mathrm{NaCl}$ and $0.1 \%$ Tween 20

$(\mathrm{v} / \mathrm{v})$ ) for $16-20 \mathrm{~h}$ at $4{ }^{\circ} \mathrm{C}$ and were incubated with the primary antibody for $16-20 \mathrm{~h}$ at $4{ }^{\circ} \mathrm{C}$ : GluA1 (1:2000, Cell Signaling cat. no. D4N9V, predicted molecular weight $100 \mathrm{kDa}$, observed band $\sim 100 \mathrm{kDa}$ ), pGluA1 Ser-845 (1:200, Cell Signaling cat. no. D10G5, predicted molecular weight $100 \mathrm{kDa}$, observed band $\sim 100 \mathrm{kDa}$ ), GluN2A (1:200, Santa Cruz Biotechnology cat. no. sc-9056, predicted molecular weight $177 \mathrm{kDa}$, observed band $\sim 170$ kDa), pGluN2A Tyr-1325 (1:200, PhosphoSolutions cat. no. p1514-1325, predicted molecular weight $180 \mathrm{kDa}$, observed band $180 \mathrm{kDa}$ ), GluN2B (1:200, Santa Cruz cat. no. sc-9057, predicted molecular weight $178 \mathrm{kDa}$, observed band $180 \mathrm{kDa}$ ), pGluN2B Tyr-1472 (1:200, Cell Signaling cat. no. 4208S, predicted molecular weight $190 \mathrm{kDa}$, observed band $\sim 180 \mathrm{kDa}$ ), GABA (1:100, PhosphoSolutions cat. no. 850-GA6, predicted molecular weight $57 \mathrm{kDa}$, observed band $\sim 57 \mathrm{kDa}$ ) and antibody to PSD-95 (1:500, Millipore, cat. no. 04-1066, predicted band size $95 \mathrm{kDa}$, observed band $\sim 95 \mathrm{kDa}$ ). Blots were then washed three times for $15 \mathrm{~min}$ in TBST, and then incubated for $1 \mathrm{~h}$ at room temperature $\left(24{ }^{\circ} \mathrm{C}\right)$, appropriately with horseradish peroxide-conjugated goat antibody to rabbit or horseradish peroxide-conjugated goat antibody to mouse $(1: 10,000$, BioRad) in TBST. After another three washes for 15 min with TBST, immunoreactivity was detected using SuperSignal West Dura chemiluminescence detection reagent (Thermo Scientific) and collected using HyBlot CL Autoradiography film (Denville Scientific) and a Kodak film processor. Following chemiluminescence detection, blots were stripped for 20 minutes at room temperature (Restore, Thermo Scientific) and reprobed for total protein levels of $\beta$ Tubulin (1:4000, Santa Cruz cat. no.sc-53140, predicted molecular weight $50 \mathrm{kDa}$, observed band $\sim 50 \mathrm{kDa}$ ), for normalization purposes. Densitometry was performed using ImageStudio software (Li-Cor Biosciences). X-ray films were digitally scanned at 600 dpi resolution, then bands of interest were selected in identically sized selection boxes within the imaging program which included a 3 pixel extended rectangle for assessment of the background signal. The average signal of the pixels in the 'background' region (between the exterior border of the region of interest selection box and the additional 3 pixel border) was then subtracted from the signal value calculated for the band of interest. This was repeated for $\beta$ Tubulin, and the signal value of the band of interest following subtraction of the background calculation was then expressed as a ratio of the corresponding $\beta$-Tubulin signal (following background subtraction). This ratio of expression for each band was then expressed as a percent of the drug naïve control animals included on the same blot.

\section{Electron Microscopy}

For electron microscopy analysis, reinstated rats $(\mathrm{n}=2)$ and control rats $(\mathrm{n}=2)$ were perfused with $2 \%$ paraformaldehyde and $2.5 \%$ of glutaraldehyde in $0.15 \mathrm{M}$ sodium cacodylate buffer ( $\mathrm{pH}$ 7.4). Brains were removed from the skull and were post fixed with $1 \%$ of osmium followed with $2 \%$ of uranyl acetate on ice for $4 \mathrm{~h}$ and were dehydrated in serial ethanol solutions followed by dry acetone. DG enriched tissue blocks were infiltrated and embedded in durcupan. For flat embedding of the sections, thin flexible molds were employed to lay the sections as level as possible in LX112 embedding media and then overlaid with plastic coverslips. The flat embedded blocks were visually trimmed to molecular regions of the hippocampus and thin sectioned to $60 \mathrm{~nm}$. Grids were viewed unstained using FEI Tecnai EM scope at the electron microscopy core at UCSD and 
micrographs were taken at $9300 \times$ magnification. Synaptic post synaptic density (PSD) was visually and qualitatively examined.

\section{Analysis of microglial cells}

Sections of the hippocampus, -2.56 to $-3.8 \mathrm{~mm}$ to bregma were stained with rabbit antiIba-1 (019-19741, 1:1000; Wako) to determine changes in structure of microglial cells. To evaluate Iba1 morphology, a Zeiss Axiophot microscope and a computer-based system (Neurolucida; Micro-BrightField) was used to generate three-dimensional cell tracings that were subsequently visualized and analyzed using NeuroExplorer (MicroBrightField). In order for a cell to be selected the following four criteria were met: (1) the cell was in the region of interest (in the hilus touching the outer granule cell layer of the superior or inferior blade), (2) the cell was distinct from other surrounding cells to allow for identification of processes, (3) the cell was not truncated or broken, and (4) the cell exhibited dark, well filled staining (Figure 8a-b).

For each animal, 6 cells were traced at 40x magnification with an oil immersion lens (equipped with a $10 \times$ eye piece), and morphological measurements were analyzed separately. A 3D Sholl analysis was performed in which concentric spheres of increasing radius (starting sphere $5 \mu \mathrm{m}$ and increasing in $1 \mu \mathrm{m}$ increments) were layered around the cell body until processes were completely encompassed. For each reconstructed cell, an estimate of area of the cell body and length of processes was obtained using the Sholl ring method.

\section{Statistical Analyses}

The methamphetamine self-administration data is expressed as the total number of lever responses during the sessions and the mean $\mathrm{mg} / \mathrm{kg}$ intake per session of methamphetamine self-administration. The effect of session duration on methamphetamine self-administration during the $6 \mathrm{~h}$ session was examined over the 14 escalation sessions using a repeatedmeasures analysis of variance (ANOVA) followed by the Student-Newman-Keuls post hoc test. The pattern of responding for methamphetamine is expressed as the mean $\mathrm{mg} / \mathrm{kg}$ per hour over $6 \mathrm{~h}$ sessions and active and inactive lever responses were compared between the first and $>5^{\text {th }}$ escalation sessions. Differences in the rate of responding between the first and other escalation sessions were evaluated using the paired $t$-test. The effect of methamphetamine withdrawal on extinction and reinstatement was examined using a repeated-measures (ANOVA) followed by the Student-Newman-Keuls post hoc test. For the Fos, Western blotting analyses and Iba1 analysis, unpaired $t$ test was used to compare raw data between controls and methamphetamine groups. For electrophysiological studies, frequency and amplitude sEPSCs were analyzed and visually confirmed using Clampfit 10.4 software (Molecular Devices). Averages of EPSC characteristics were based on a time interval of 90s and a minimum of three sweeps. All detected events were used for event frequency and amplitude analysis. Statistical comparisons were made using one-way ANOVA followed by the Student-Newman-Keuls post hoc test. The data are expressed as mean \pm SEM in all graphs. 


\section{Results}

\section{Extended access to Meth self-administration resulted in escalation of Meth intake}

Rats experienced Meth self-administration for 14 days (Figure 1b-c). Repeated measures two-way ANOVA detected a significant session $\times$ lever interaction (Figure $1 \mathrm{~b}, \mathrm{~F}_{13,442}=6.7$, $\mathrm{p}<0.0001$ ), a significant effect of lever (Figure $1 b, F_{1,34}=22.8, p<0.0001$ ) and a significant effect of session (Figure 1b, $\mathrm{F}_{13,442}=6.7, \mathrm{p}<0.0001$ ). Post hoc analysis revealed a significant increase in active lever presses for Meth during the $6 \mathrm{~h}$ session in extended access animals during session 7-14 compared with session 1. No significant changes were observed in inactive lever responses. Furthermore, Meth intake also increased between session 7-14 compared to session 1 (Figure 1c, $F_{19,247}=41.2$, $\mathrm{p}<0.001$ ).

\section{Methamphetamine addicted animals extinguish operant behavior and demonstrate reinstatement of methamphetamine seeking triggered by methamphetamine context and cues}

After 12 days of forced abstinence from methamphetamine, rats experienced extinction sessions. During extinction sessions, methamphetamine was not available and lever responding readily declined across daily 1-hour extinction sessions, as seen in Figure 2 (repeated measures two-way ANOVA; effect of day, $F_{5,170}=4.6, \mathrm{p}=0.001$; a significant effect of lever (Figure 2, $\mathrm{F}_{1,34}=20.6, \mathrm{p}<0.0001$ ) and a significant lever $\times$ session interaction, $\left.\mathrm{F}_{5,170}=6.5, \mathrm{p}=0.001\right)$. Post-hoc analysis demonstrated higher responding on the first day of extinction compared with days 3-6 (Figure 2; $\mathrm{p}<0.05$ ). Following extinction, rats were tested on context-driven reinstatement and contextual-cued reinstatement (Figure 3a, b). All rats showed higher responding on the previously drug-paired lever during context-induced and cued reinstatement when compared with the last extinction session (paired $t$ test; $\mathrm{ps}=$ $0.01)$.

\section{Baseline spontaneous DG glutamatergic transmission is elevated in methamphetamine rats that reinstated methamphetamine seeking}

We assessed baseline spontaneous glutamatergic synaptic transmission using whole-cell voltage clamp recordings of spontaneous excitatory postsynaptic currents (sEPSCs) in the GCNs in the dorsal DG from naïve control and methamphetamine experienced rats (Figure 4a-c). Methamphetamine rats were either euthanized 16-18h after the self-administration session (Meth), during protracted abstinence (Meth $\mathrm{Ab}$ ), $1 \mathrm{~h}$ after extinction session (Meth Ext) or $1 \mathrm{~h}$ after reinstatement session (Meth Rst). GCNs from rats that demonstrated robust reinstatement of methamphetamine seeking had a significantly higher sEPSC frequency compared to GCNs from naïve control and other methamphetamine groups $\left(\mathrm{F}_{4,46}=11.24\right.$, $\mathrm{p}<$ 0.0001 by one-way ANOVA; Figure 4d). Post hoc analysis by Newman-Keuls multiple comparisons test demonstrated higher sEPSC frequency in reinstated rats compared to all other groups ( $\mathrm{ps}<0.01$ ). Cumulative distribution of sEPSCs $>10 \mathrm{pA}$ demonstrated greater percentage of higher amplitude in reinstated rats compared with naïve control group by Kolmogorov-Smimov test ( $\mathrm{p}=0.046$; Kolmogorov-Smimov $\mathrm{D}=0.22$; Figure 4f). 


\section{Analysis of Fos demonstrates enhanced neuronal activation in reinstated rats}

To confirm the activation of GCNs after reinstatement of methamphetamine seeking, Fos positive cells were counted in control and reinstated rats. The number of Fos cells from control rats were lower than reinstated rats ( $\mathrm{p}=0.0002$ by unpaired $t$ test), indicating enhanced neuronal activation in reinstated rats (Figure $4 \mathrm{~g}$ ).

\section{Intrinsic firing properties of GCNs are altered in rats that reinstated methamphetamine seeking}

We next studied the active and passive membrane properties of the GCNs from the dorsal DG in rats from control and all other methamphetamine groups (Figure 5a-i). GCNs from reinstated rats and acute withdrawn rats showed depolarized resting potentials compared with controls, and rats that experienced abstinence or abstinence followed by extinction (Figure 5e; $\mathrm{F}_{4,43}=20.49$, $\mathrm{p}<0.0001$ by one-way ANOVA). Post hoc analysis revealed significant differences between controls, abstinence and extinction rats and acute withdrawal and reinstated rats $(\mathrm{ps}<0.01)$. GCNs from reinstated rats and acute withdrawn rats showed lower input resistance compared with other groups (Figure $5 f ; \mathrm{F}_{4,49}=5.04$, $\mathrm{p}=0.001$ by oneway ANOVA). Post hoc analysis revealed significant decreases in reinstated rats compared with controls, abstinence and extinction rats and decreases in acute withdrawal rats compared with rats that experienced abstinence or abstinence followed by extinction $(\mathrm{ps}<0.05)$. Repeated measures two-way ANOVA demonstrated a significant difference in inter-spike interval (ISI), measured as spike latency between first and second spike peak (no interaction, no effect of treatment and significant effect of ISI; F $1,28=15.09, \mathrm{p}=0.006$ ). Post hoc analysis showed higher latency to spike between the first and second spike in GCNs from acute withdrawn and reinstated rats ( $\mathrm{ps}<0.05$, Figure $5 \mathrm{~g}$ ). GCNs from reinstated rats showed lower fAHP compared with other groups (Figure $5 \mathrm{~h} ; \mathrm{F}_{4,34}=2.58$, $\mathrm{p}=0.05$ by oneway ANOVA). Post hoc analysis revealed significant decreases in reinstated rats compared with controls, acute withdrawal, abstinence and extinction rats (ps $<0.05$ ). GCNs from all groups were able to generate fast action potentials with large amplitudes that were elicited by depolarizing current injections (Figure 5i). The number of spikes elicited by GCNs from each group with increasing current injections in current-clamp recording were determined, and two-way ANOVA demonstrated a significant number of spikes $\times$ treatment interaction $\left(\mathrm{F}_{52,714}=2.8, \mathrm{p}<0.001\right)$, significant increases in the number of spikes over current injections $\left(\mathrm{F}_{13,714}=157.3, \mathrm{p}<0.001\right)$ and significant effect of treatment $\left(\mathrm{F}_{4,714}=56.6\right.$, $\mathrm{p}<0.001)$. Post hoc analysis demonstrates that reinstated rats have reduced number of spikes with increasing current injections compared to all other groups from current injections ranging from $100 \mathrm{pA}$ to $260 \mathrm{pA}$ (Figure $5 \mathrm{i}$; ps $<0.05$ ). The reduced number of spikes were not due to alterations in time to peak, rise slope to threshold, peak amplitude, half-width, decay slope, slow AHP, rheobase current or spike threshold (Figure 5j; n.s.). At higher current injections ( $>300 \mathrm{pA})$, there were no significant differences in the number of spikes between drug naïve rats and other groups, indicating that GCNs from all groups elicited property of regular spiking by depolarizing current injections (data not shown). 


\section{Expression of and activation of glutamatergic receptors and expression of $\mathrm{GABA}_{A}$ receptors in the dorsal DG is altered by reinstatement of methamphetamine seeking}

To determine whether reinstatement of methamphetamine seeking altered expression of GluA and GluN subunits, GluA, GluN2A and GluN2B in the dorsal DG, phosphorylated and total receptor protein levels were analyzed in drug naïve control and methamphetamine rats (Figure 6a). We also determined alterations in PSD protein as measured by changes in expression of PSD-95 and GABA receptors by measuring changes in $\mathrm{GABA}_{\mathrm{A}}$ subunits. Data was subjected to unpaired $t$-test to examine the effects of treatment (control vs. methamphetamine reinstatement group) and analysis showed no changes in GluA levels, however showed significant increases in total GluN2A subunits, decreases in phosphorylated GluN2B subunits, decreases in $\mathrm{GABA}_{\mathrm{A}}$ levels and increases in PSD-95 compared to drug naïve controls (Figure 6b-c; ps < 0.05). There was no change in the GluN2A/GluN2B ratio in rats that reinstated methamphetamine seeking compared with drug naïve controls (Figure 6d; n.s.).

\section{Electron microscopy analysis demonstrates enhanced expression of synaptic PSD in reinstated rats}

To confirm immunoblotting revealed enhances in PSD-95 expression in reinstated rats, electron microscopy was performed on brain tissue collected one hour after reinstatement sessions. Compared to control rats, reinstated rats demonstrate greater number of synaptic PSD in the molecular layer of the DG (Figure 7a). Qualitative analysis demonstrated greater intensity of synaptic PSD in reinstated rats (Figure 7b-c).

\section{Analysis of Iba-1 demonstrates a lack of neuroimmune response in reinstated rats}

To confirm the absence of microglial activation, 3D Sholl analysis of Iba-1 positive cells was performed in control and reinstated rats. Iba- 1 cells from control and reinstated rats did not differ in cell soma area and total dendritic length (n.s.), indicating an absence of microglial activation in reinstated rats (Figure 8a-d).

\section{Discussion}

The reinstatement of drug-seeking behavior is a valid animal model of relapse and contextdriven methamphetamine seeking is linked to maladaptive plasticity in the hippocampus (Shaham et al., 2003; Hiranita et al., 2006; Galinato et al., 2017). For example, the dorsal hippocampus is particularly critical for acquisition of drug memories and reconsolidation of reactivated drug-related associative memories (Meyers et al., 2006; Wells et al., 2011), suggesting that the act of drug taking and seeking produces neuroadaptive changes in the dorsal hippocampus that allow for long-term memory storage of drug-context memories, and allow the recall of associative memories during relapse. Our findings demonstrate that methamphetamine addicted animals show profound context-driven reinstatement of methamphetamine seeking weeks after abstinence, and these behavioral effects were associated with dysregulated spontaneous glutamatergic synaptic transmission in the dorsal DG GCNs in the basal state, in concert with neuronal activation, altered expression of GluNs, reduced $\mathrm{GABA}_{\mathrm{A}}$ and enhanced PSD-95 in the dorsal DG and ultrastructural changes in the molecular layer of the dorsal DG. This is an important finding because the alterations 
in functional plasticity of GCNs were significant in reinstated rats compared with rats that experienced acute withdrawal, protracted abstinence or extinction without any reinstatement sessions, indicating that reinstatement of methamphetamine seeking predicts enhanced spontaneous activity and reduced intrinsic excitability of GCNs in the hippocampus. Given the significance of the dorsal hippocampus in the behavioral aspects of context-driven methamphetamine seeking, it is likely that the heightened glutamatergic state in the dorsal DG contributes to the increased propensity for relapse in methamphetamine-addicted rats.

The electrophysiological results indicate that DG GCNs from reinstated rats have dysregulated neuronal functioning in the basal state. For example, within the DG, GCNs from reinstated rats have an increased level of spontaneous glutamatergic activity as compared to drug naïve controls and other methamphetamine groups, with enhanced frequency and amplitude of sEPSCs. Generally, changes in the frequency of EPSCs reflect changes in the probability of glutamate release, while changes in EPSC amplitude and kinetics reflect change in postsynaptic glutamatergic receptor function (De Koninck \& Mody, 1994). Notably, reinstated rats also demonstrated altered active and passive membrane properties of GCNs, where GCNs had reduced number of action potential generation with increased depolarizing current injections compared to drug naïve controls and other methamphetamine groups. One contributing factor is that, GCNs in reinstated rats have lower membrane properties that favor decreased number of action potential generation with similar current stimuli compared with naïve controls, and these effects could be facilitated by loss of or less functional glutamate receptors (Spruston et al., 1995). Another contributing factor is that GCNs in reinstated rats have lower fAHP. In the DG GCNs, amplified or reduced fAHP amplitude can influence action potential generation via alterations in inter-spike interval, and this exclusively occurs via large-conductance calciumand voltage-activated potassium (BK) channel activation through ryanodine receptors (Brenner et al., 2005; Mehranfard et al., 2015; Wang et al., 2016). Therefore, it is possible that reduced firing properties of GCNs from reinstated rats could be associated with altered activation of BK channels via ryanodine receptors (Lin et al., 2016). Because our experiments did not incorporate pharmacological isolation of action potential generation, this hypothesis needs to be tested.

We speculate two reasons for altered spontaneous glutamatergic synaptic transmission in GCNs from reinstated rats compared with naïve controls. First, the enhanced sEPSCs of GCNs in reinstated rats could be due to methamphetamine-induced alterations in tonic GABAergic inhibition that is maintained in the DG. For example, tonic GABAergic inhibition has been proposed to maintain the integrity of the DG-mediated regulation of the hippocampal trisynaptic pathway (Coulter \& Carlson, 2007). Control animals exhibit a hyperpolarized resting membrane potential compared to the reinstated rats, and this was associated with higher membrane resistance in control rats compared to reinstated rats. Given that DG GCNs exhibit low firing rates and their resting membrane potential is hyperpolarized compared to other principal neurons (Scharfman \& Schwartzkroin, 1989; Jung \& McNaughton, 1993), and that these effects are mediated by tonic GABAergic conductance in the GCNs (Stell et al., 2003; Glykys \& Mody, 2006; Herd et al., 2008), it can be considered that methamphetamine induced alterations in GABA and glutamate levels could be facilitating the altered functional properties of GCNs in reinstated rats (Han et al., 
2012; Bu et al., 2013). For example, ambient GABA acting on extrasynaptic $\mathrm{GABA}_{\mathrm{A}}$ receptors emanates from synaptic release (Glykys \& Mody, 2007) and dendrites (Zilberter et al., 1999), and the number of available $\mathrm{GABA}_{\mathrm{A}}$ receptors rather than receptor kinetics and affinity dictate tonic GABAergic conductance (De Koninck \& Mody, 1994). We have recently demonstrated that reinstatement of methamphetamine seeking reduces structural plasticity of apical dendrites of GCNs (Galinato et al., 2017), and current findings show reduced expression of $\mathrm{GABA}_{\mathrm{A}}$ receptors in the $\mathrm{DG}$. These results indicate that dendritic alterations in concert with reduced $\mathrm{GABA}_{\mathrm{A}}$ receptors during abstinence may contribute to reduced tonic GABAergic inhibition in the DG. Furthermore, binge methamphetamine experience causes activation of microglia in the DG (Buchanan et al., 2010), which may lead to the inhibition of glutamine uptake and glutamine synthesis and hence reduction in GABA (Morris \& Bachelard, 2003; Zou \& Crews, 2005) in the DG. However, our findings do not support the contribution of microglial activation in the DG to reduced GABAergic conductance in the DG, and therefore suggest that a mechanism at the network level could be contributing for altered functional activity of GCNs.

Second, context-driven methamphetamine seeking-induced altered sEPSCs of GCNs could be associated with alterations in the expression of plasticity-related proteins regulating neuronal function. For example, modulation of long-lasting synaptic strength requires activity induced synthesis of plasticity-related proteins to sustain morphological and functional changes of synapses that are crucial for the establishment and consolidation of long-term memory in the hippocampus; in our studies, drug-context memory. In this context, the spatiotemporal organization of neurotransmitter receptors in postsynaptic membranes is a fundamental determinant of synaptic transmission, and the molecular composition and organization of GluNs in the postsynaptic membrane is a fundamental determinant of the quality of the synapse (Wheal et al., 1998; Nikonenko et al., 2002; Shinohara \& Hirase, 2009). Notably, at mature synapses, GluN2A-rich receptors are associated with enhanced PSD95 expression and located principally at the postsynaptic density (Licznerski \& Duman, 2013; Shipton \& Paulsen, 2014). Our findings of increased GluN2A expression in addition with increased PSD95 expression and synaptic PSD could be associated with increased number of mature synapses in the DG in reinstated rats. These biochemical and ultrastructural findings add to the electrophysiological findings of more depolarized resting membrane potential and reduced membrane resistance of GCNs which are indicative of increases in cell maturation (Liu et al., 1996; Liu et al., 2000). In concert with biochemical and electrophysiological findings of enhanced maturity of GCNs, our findings also indicate reduced phosphorylation of GluN2B subunits. Dephosphorylation of GluN2B subunits support alterations in receptor function, (Ali \& Salter, 2001; Nakazawa et al., 2001; Nakazawa et al., 2006), with phosphorylation of GluN2B at Tyr-1472 regulating internalization of GluNs via clathrin-mediated endocytosis, such that phosphorylation suppresses GluN endocytosis and dephosphorylation enhances GluN endocytosis (Lavezzari et al., 2003; Prybylowski et al., 2005). Dephosphorylation of GluN2B by methamphetamine may thus alter active firing properties of GCNs (Nikonenko et al., 2002). One limitation of the present study is the lack of direct comparison of biochemical and immunohistochemical findings between methamphetamine animals that experienced abstinence only without extinction and reinstatement, extinction only without reinstatement and animals that 
demonstrated context-driven reinstatement. Inevitably, the fact that animals that experienced abstinence and extinction did not significantly differ from methamphetamine naïve group in basal neuronal transmission and neuronal excitability suggests that some caution is warranted when interpreting the observed functional changes, and biochemical and immunohistochemical changes. Nevertheless, these observations from behavioral, electrophysiological, biochemical, immunohistochemical and ultrastructural studies indicate that context-driven reinstatement of methamphetamine seeking modifies DG plasticity, producing specific alterations in intrinsic spiking and elevated spontaneous glutamate synaptic transmission in the GCNs that may contribute to the altered synaptic connectivity neuronal circuitry - and activity.

\section{Acknowledgments}

This work was supported by grants from the National Science Foundation, USA (DGE-1144086 to M.H.G), National Institute on Drug Abuse, USA (DA034140 to C.D.M.) and National Institute of Alcoholism and Alcohol Abuse, USA (AA020098, AA06420 to C.D.M.). We sincerely thank Dr. Bryan W. Luikart from the Geisel School of Medicine, Dartmouth College, for his scientific collaboration and extensive discussion on the electrophysiological data. We thank Dr. Brian Head from the department of anesthesiology UCSD for his scientific collaboration on the electron microscopy (EM) studies. We thank Ying Jones at the UCSD EM core for preparation of the brain samples and training on the EM. We thank Ryan Ostrom from the division of biological sciences independent study program at UCSD and Jasmine Guevara from the NIDA summer internship program for assistance with animal behavior.

\section{References}

Ali DW, Salter MW. NMDA receptor regulation by Src kinase signalling in excitatory synaptic transmission and plasticity. Curr Opin Neurobiol. 2001; 11:336-342. [PubMed: 11399432]

Amaral DG, Witter MP. The three-dimensional organization of the hippocampal formation: a review of anatomical data. Neuroscience. 1989; 31:571-591. [PubMed: 2687721]

Andersen P, Bliss TV, Skrede KK. Unit analysis of hippocampal polulation spikes. Exp Brain Res. 1971; 13:208-221. [PubMed: 5123965]

Andersen P, Holmqvist B, Voorhoeve PE. Entorhinal activation of dentate granule cells. Acta Physiol Scand. 1966a; 66:448-460. [PubMed: 5927271]

Andersen P, Holmqvist B, Voorhoeve PE. Excitatory synapses on hippocampal apical dendrites activated by entorhinal stimulation. Acta Physiol Scand. 1966b; 66:461-472. [PubMed: 5927272]

Benedetti BL, Takashima Y, Wen JA, Urban-Ciecko J, Barth AL. Differential wiring of layer 2/3 neurons drives sparse and reliable firing during neocortical development. Cereb Cortex. 2013; 23:2690-2699. [PubMed: 22918982]

Brenner R, Chen QH, Vilaythong A, Toney GM, Noebels JL, Aldrich RW. BK channel beta4 subunit reduces dentate gyrus excitability and protects against temporal lobe seizures. Nat Neurosci. 2005; 8:1752-1759. [PubMed: 16261134]

Bu Q, Lv L, Yan G, Deng P, Wang Y, Zhou J, Yang Y, Li Y, Cen X. NMR-based metabonomic in hippocampus, nucleus accumbens and prefrontal cortex of methamphetamine-sensitized rats. Neurotoxicology. 2013; 36:17-23. [PubMed: 23462569]

Buchanan JB, Sparkman NL, Johnson RW. A neurotoxic regimen of methamphetamine exacerbates the febrile and neuroinflammatory response to a subsequent peripheral immune stimulus. Journal of neuroinflammation. 2010; 7:82. [PubMed: 21092194]

Burgess N, Maguire EA, O'Keefe J. The human hippocampus and spatial and episodic memory. Neuron. 2002; 35:625-641. [PubMed: 12194864]

Coulter DA, Carlson GC. Functional regulation of the dentate gyrus by GABA-mediated inhibition. Prog Brain Res. 2007; 163:235-243. [PubMed: 17765722] 
Criado JR, Gombart LM, Huitron-Resendiz S, Henriksen SJ. Neuroadaptations in dentate gyrus function following repeated methamphetamine administration. Synapse. 2000; 37:163-166. [PubMed: 10881037]

Crombag HS, Gorny G, Li Y, Kolb B, Robinson TE. Opposite effects of amphetamine selfadministration experience on dendritic spines in the medial and orbital prefrontal cortex. Cereb Cortex. 2005; 15:341-348. [PubMed: 15269111]

Daumann J, Koester P, Becker B, Wagner D, Imperati D, Gouzoulis-Mayfrank E, Tittgemeyer M. Medial prefrontal gray matter volume reductions in users of amphetamine-type stimulants revealed by combined tract-based spatial statistics and voxel-based morphometry. Neuroimage. 2011; 54:794-801. [PubMed: 20817105]

De Koninck Y, Mody I. Noise analysis of miniature IPSCs in adult rat brain slices: properties and modulation of synaptic GABAA receptor channels. J Neurophysiol. 1994; 71:1318-1335. [PubMed: 8035217]

Fuchs RA, Evans KA, Ledford CC, Parker MP, Case JM, Mehta RH, See RE. The role of the dorsomedial prefrontal cortex, basolateral amygdala, and dorsal hippocampus in contextual reinstatement of cocaine seeking in rats. Neuropsychopharmacology. 2005; 30:296-309. [PubMed: 15483559]

Galinato MH, Lockner JW, Fannon-Pavlich MJ, Sobieraj JC, Staples MC, Somkuwar SS, Ghofranian A, Chaing S, Navarro AI, Joea A, Luikart BW, Janda KD, Heyser C, Koob GF, Mandyam CD. A synthetic small-molecule Isoxazole-9 protects against methamphetamine relapse. Mol Psychiatry. 2017

Galinato MH, Orio L, Mandyam CD. Methamphetamine differentially affects BDNF and cell death factors in anatomically defined regions of the hippocampus. Neuroscience. 2014

Galinato MH, Orio L, Mandyam CD. Methamphetamine differentially affects BDNF and cell death factors in anatomically defined regions of the hippocampus. Neuroscience. 2015; 286:97-108. [PubMed: 25463524]

Glykys J, Mody I. Hippocampal network hyperactivity after selective reduction of tonic inhibition in GABA A receptor alpha5 subunit-deficient mice. J Neurophysiol. 2006; 95:2796-2807. [PubMed: 16452257]

Glykys J, Mody I. The main source of ambient GABA responsible for tonic inhibition in the mouse hippocampus. J Physiol. 2007; 582:1163-1178. [PubMed: 17525114]

Han W, Wang F, Qi J, Wang F, Zhang L, Zhao S, Song M, Wu C, Yang J. NMDA receptors in the medial prefrontal cortex and the dorsal hippocampus regulate methamphetamine-induced hyperactivity and extracellular amino acid release in mice. Behav Brain Res. 2012; 232:44-52. [PubMed: 22808522]

Herd MB, Haythornthwaite AR, Rosahl TW, Wafford KA, Homanics GE, Lambert JJ, Belelli D. The expression of GABAA beta subunit isoforms in synaptic and extrasynaptic receptor populations of mouse dentate gyrus granule cells. J Physiol. 2008; 586:989-1004. [PubMed: 18079158]

Hiranita T, Nawata Y, Sakimura K, Anggadiredja K, Yamamoto T. Suppression of methamphetamineseeking behavior by nicotinic agonists. Proc Natl Acad Sci U S A. 2006; 103:8523-8527. [PubMed: 16717181]

Jung MW, McNaughton BL. Spatial selectivity of unit activity in the hippocampal granular layer. Hippocampus. 1993; 3:165-182.

Kim A, Zamora-Martinez ER, Edwards S, Mandyam CD. Structural reorganization of pyramidal neurons in the medial prefrontal cortex of alcohol dependent rats is associated with altered glial plasticity. Brain Struct Funct. 2015; 220:1705-1720. [PubMed: 24667898]

Kim YT, Lee JJ, Song HJ, Kim JH, Kwon DH, Kim MN, Yoo DS, Lee HJ, Kim HJ, Chang Y. Alterations in cortical activity of male methamphetamine abusers performing an empathy task: fMRI study. Hum Psychopharmacol. 2010; 25:63-70. [PubMed: 20041477]

Lavezzari G, McCallum J, Lee R, Roche KW. Differential binding of the AP-2 adaptor complex and PSD-95 to the C-terminus of the NMDA receptor subunit NR2B regulates surface expression. Neuropharmacology. 2003; 45:729-737. [PubMed: 14529712]

Licznerski P, Duman RS. Remodeling of axo-spinous synapses in the pathophysiology and treatment of depression. Neuroscience. 2013; 251:33-50. [PubMed: 23036622] 
Lin M, Sambo D, Khoshbouei H. Methamphetamine Regulation of Firing Activity of Dopamine Neurons. J Neurosci. 2016; 36:10376-10391. [PubMed: 27707972]

Liu X, Tilwalli S, Ye G, Lio PA, Pasternak JF, Trommer BL. Morphologic and electrophysiologic maturation in developing dentate gyrus granule cells. Brain Res. 2000; 856:202-212. [PubMed: 10677627]

Liu YB, Lio PA, Pasternak JF, Trommer BL. Developmental changes in membrane properties and postsynaptic currents of granule cells in rat dentate gyrus. J Neurophysiol. 1996; 76:1074-1088. [PubMed: 8871221]

Mandyam CD, Norris RD, Eisch AJ. Chronic morphine induces premature mitosis of proliferating cells in the adult mouse subgranular zone. Journal of Neuroscience Research. 2004; 76:783-794. [PubMed: 15160390]

Mandyam CD, Wee S, Crawford EF, Eisch AJ, Richardson HN, Koob GF. Varied access to intravenous methamphetamine self-administration differentially alters adult hippocampal neurogenesis. Biol Psychiatry. 2008; 64:958-965. [PubMed: 18490002]

Mehranfard N, Gholamipour-Badie H, Motamedi F, Janahmadi M, Naderi N. Long-term increases in BK potassium channel underlie increased action potential firing in dentate granule neurons following pilocarpine-induced status epilepticus in rats. Neurosci Lett. 2015; 585:88-91. [PubMed: 25434869]

Meyers RA, Zavala AR, Speer CM, Neisewander JL. Dorsal hippocampus inhibition disrupts acquisition and expression, but not consolidation, of cocaine conditioned place preference. Behav Neurosci. 2006; 120:401-412. [PubMed: 16719704]

Morales AM, Lee B, Hellemann G, O'Neill J, London ED. Gray-matter volume in methamphetamine dependence: cigarette smoking and changes with abstinence from methamphetamine. Drug Alcohol Depend. 2012; 125:230-238. [PubMed: 22445480]

Morris P, Bachelard H. Reflections on the application of 13C-MRS to research on brain metabolism. NMR in biomedicine. 2003; 16:303-312. [PubMed: 14679497]

Nakama H, Chang L, Fein G, Shimotsu R, Jiang CS, Ernst T. Methamphetamine users show greater than normal age-related cortical gray matter loss. Addiction. 2011; 106:1474-1483. [PubMed: 21438934]

Nakazawa T, Komai S, Tezuka T, Hisatsune C, Umemori H, Semba K, Mishina M, Manabe T, Yamamoto T. Characterization of Fyn-mediated tyrosine phosphorylation sites on GluR epsilon 2 (NR2B) subunit of the N-methyl-D-aspartate receptor. J Biol Chem. 2001; 276:693-699. [PubMed: 11024032]

Nakazawa T, Komai S, Watabe AM, Kiyama Y, Fukaya M, Arima-Yoshida F, Horai R, Sudo K, Ebine K, Delawary M, Goto J, Umemori H, Tezuka T, Iwakura Y, Watanabe M, Yamamoto T, Manabe T. NR2B tyrosine phosphorylation modulates fear learning as well as amygdaloid synaptic plasticity. Embo j. 2006; 25:2867-2877. [PubMed: 16710293]

Nikonenko I, Jourdain P, Alberi S, Toni N, Muller D. Activity-induced changes of spine morphology. Hippocampus. 2002; 12:585-591. [PubMed: 12440574]

Orikabe L, Yamasue H, Inoue H, Takayanagi Y, Mozue Y, Sudo Y, Ishii T, Itokawa M, Suzuki M, Kurachi M, Okazaki Y, Kasai K. Reduced amygdala and hippocampal volumes in patients with methamphetamine psychosis. Schizophr Res. 2011; 132:183-189. [PubMed: 21784619]

Price KL, DeSantis SM, Simpson AN, Tolliver BK, McRae-Clark AL, Saladin ME, Baker NL, Wagner MT, Brady KT. The impact of clinical and demographic variables on cognitive performance in methamphetamine-dependent individuals in rural South Carolina. Am J Addict. 2011; 20:447-455. [PubMed: 21838844]

Prybylowski K, Chang K, Sans N, Kan L, Vicini S, Wenthold RJ. The synaptic localization of NR2Bcontaining NMDA receptors is controlled by interactions with PDZ proteins and AP-2. Neuron. 2005; 47:845-857. [PubMed: 16157279]

Recinto P, Samant AR, Chavez G, Kim A, Yuan CJ, Soleiman M, Grant Y, Edwards S, Wee S, Koob GF, George O, Mandyam CD. Levels of neural progenitors in the hippocampus predict memory impairment and relapse to drug seeking as a function of excessive methamphetamine selfadministration. Neuropsychopharmacology. 2012; 37:1275-1287. [PubMed: 22205547] 
SAMHSA. Results from the 2007 National Survey on Drug Use and Health: Detailed Tables. Substance Abuse and Mental Health Services Administration, Office of Applied Studies. 2008

Scharfman HE, Schwartzkroin PA. Protection of dentate hilar cells from prolonged stimulation by intracellular calcium chelation. Science. 1989; 246:257-260. [PubMed: 2508225]

Schwartz DL, Mitchell AD, Lahna DL, Luber HS, Huckans MS, Mitchell SH, Hoffman WF. Global and local morphometric differences in recently abstinent methamphetamine-dependent individuals. Neuroimage. 2010; 50:1392-1401. [PubMed: 20096794]

Shaham Y, Shalev U, Lu L, De Wit H, Stewart J. The reinstatement model of drug relapse: history, methodology and major findings. Psychopharmacology (Berl). 2003; 168:3-20. [PubMed: 12402102]

Shinohara Y, Hirase H. Size and Receptor Density of Glutamatergic Synapses: A Viewpoint from LeftRight Asymmetry of CA3-CA1 Connections. Front Neuroanat. 2009; 3:10. [PubMed: 19587849]

Shipton OA, Paulsen O. GluN2A and GluN2B subunit-containing NMDA receptors in hippocampal plasticity. Philos Trans R Soc Lond B Biol Sci. 2014; 369:20130163. [PubMed: 24298164]

Sobieraj JC, Kim A, Fannon MJ, Mandyam CD. Chronic wheel running-induced reduction of extinction and reinstatement of methamphetamine seeking in methamphetamine dependent rats is associated with reduced number of periaqueductal gray dopamine neurons. Brain Struct Funct. 2014

Somkuwar SS, Fannon-Pavlich MJ, Ghofranian A, Quigley JA, Dutta RR, Galinato MH, Mandyam $\mathrm{CD}$. Wheel running reduces ethanol seeking by increasing neuronal activation and reducing oligodendroglial/neuroinflammatory factors in the medial prefrontal cortex. Brain Behav Immun. 2016; 58:357-368. [PubMed: 27542327]

Spruston N, Jonas P, Sakmann B. Dendritic glutamate receptor channels in rat hippocampal CA3 and CA1 pyramidal neurons. J Physiol. 1995; 482(Pt 2):325-352. [PubMed: 7536248]

Squire LR, Stark CE, Clark RE. The medial temporal lobe. Annu Rev Neurosci. 2004; 27:279-306. [PubMed: 15217334]

Stell BM, Brickley SG, Tang CY, Farrant M, Mody I. Neuroactive steroids reduce neuronal excitability by selectively enhancing tonic inhibition mediated by delta subunit-containing GABAA receptors. Proc Natl Acad Sci U S A. 2003; 100:14439-14444. [PubMed: 14623958]

Swanson LW, Wyss JM, Cowan WM. An autoradiographic study of the organization of intrahippocampal association pathways in the rat. J Comp Neurol. 1978; 181:681-715. [PubMed: 690280]

Swant J, Chirwa S, Stanwood G, Khoshbouei H. Methamphetamine reduces LTP and increases baseline synaptic transmission in the CA1 region of mouse hippocampus. PLoS ONE. 2010; 5:e11382. [PubMed: 20614033]

Thompson PM, Hayashi KM, Simon SL, Geaga JA, Hong MS, Sui Y, Lee JY, Toga AW, Ling W, London ED. Structural abnormalities in the brains of human subjects who use methamphetamine. J Neurosci. 2004; 24:6028-6036. [PubMed: 15229250]

Wang B, Bugay V, Ling L, Chuang HH, Jaffe DB, Brenner R. Knockout of the BK beta4-subunit promotes a functional coupling of BK channels and ryanodine receptors that mediate a fAHPinduced increase in excitability. J Neurophysiol. 2016; 116:456-465. [PubMed: 27146987]

Weber E, Blackstone K, Iudicello JE, Morgan EE, Grant I, Moore DJ, Woods SP. Neurocognitive deficits are associated with unemployment in chronic methamphetamine users. Drug Alcohol Depend. 2012; 125:146-153. [PubMed: 22560676]

Wells AM, Lasseter HC, Xie X, Cowhey KE, Reittinger AM, Fuchs RA. Interaction between the basolateral amygdala and dorsal hippocampus is critical for cocaine memory reconsolidation and subsequent drug context-induced cocaine-seeking behavior in rats. Learn Mem. 2011; 18:693-702. [PubMed: 22005750]

Wells AM, Xie X, Higginbotham JA, Arguello AA, Healey KL, Blanton M, Fuchs RA. Contribution of an SFK-Mediated Signaling Pathway in the Dorsal Hippocampus to Cocaine-Memory Reconsolidation in Rats. Neuropsychopharmacology. 2016; 41:675-685. [PubMed: 26202103]

Wheal HV, Chen Y, Mitchell J, Schachner M, Maerz W, Wieland H, Van Rossum D, Kirsch J. Molecular mechanisms that underlie structural and functional changes at the postsynaptic membrane during synaptic plasticity. Prog Neurobiol. 1998; 55:611-640. [PubMed: 9670221] 
Yassin L, Benedetti BL, Jouhanneau JS, Wen JA, Poulet JF, Barth AL. An embedded subnetwork of highly active neurons in the neocortex. Neuron. 2010; 68:1043-1050. [PubMed: 21172607]

Yeckel MF, Berger TW. Feedforward excitation of the hippocampus by afferents from the entorhinal cortex: redefinition of the role of the trisynaptic pathway. Proc Natl Acad Sci U S A. 1990; 87:5832-5836. [PubMed: 2377621]

Yuan CJ, Quiocho JM, Kim A, Wee S, Mandyam CD. Extended access methamphetamine decreases immature neurons in the hippocampus which results from loss and altered development of neural progenitors without altered dynamics of the S-phase of the cell cycle. Pharmacol Biochem Behav. 2011; 100:98-108. [PubMed: 21855565]

Zhao C, Teng EM, Summers RG Jr, Ming GL, Gage FH. Distinct morphological stages of dentate granule neuron maturation in the adult mouse hippocampus. J Neurosci. 2006; 26:3-11. [PubMed: 16399667]

Zilberter Y, Kaiser KM, Sakmann B. Dendritic GABA release depresses excitatory transmission between layer 2/3 pyramidal and bitufted neurons in rat neocortex. Neuron. 1999; 24:979-988. [PubMed: 10624960]

Zou JY, Crews FT. TNF alpha potentiates glutamate neurotoxicity by inhibiting glutamate uptake in organotypic brain slice cultures: neuroprotection by NF kappa B inhibition. Brain Res. 2005; 1034:11-24. [PubMed: 15713255] 


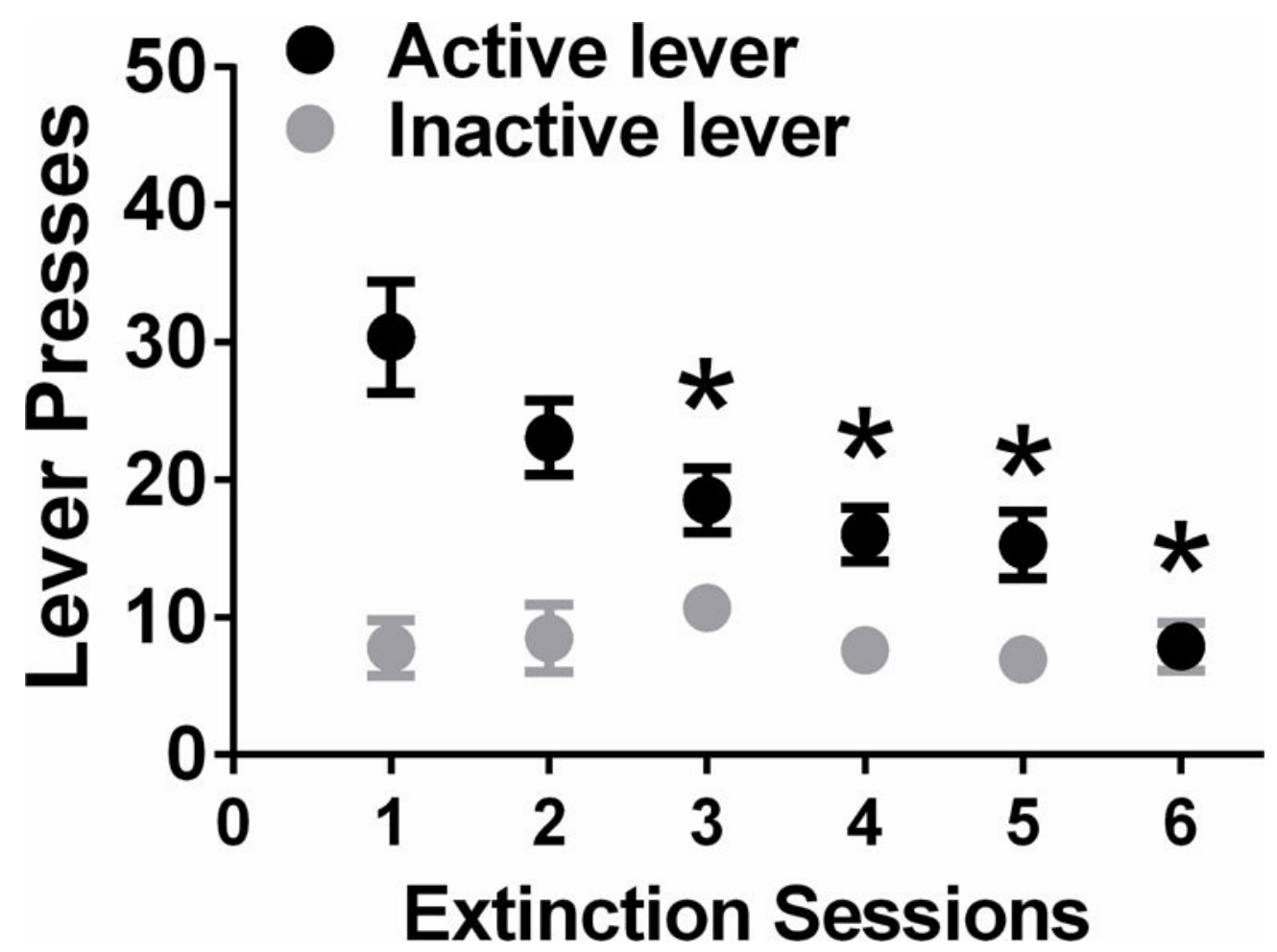

Figure 1.

(a) Schematic of experimental design indicating time frame for each type of session. Total of 5 experimental groups were used. Group 1, methamphetamine naïve controls; Group 2, methamphetamine self-administration; Group 3, methamphetamine abstinence; Group 4, methamphetamine extinction; Group 5, methamphetamine reinstatement. (b-c) Escalation of methamphetamine self-administration. (b) Lever responses during six hour methamphetamine sessions, (c) and amount of methamphetamine consumed. $\mathrm{n}=30$. Data shown are represented as mean $+/-$ SEM. $* \mathrm{P}<0.05$, compared to session 1 (b-c) by repeated measures two way analysis of variance (ANOVA) and Student-Newman-Keuls posttests. 

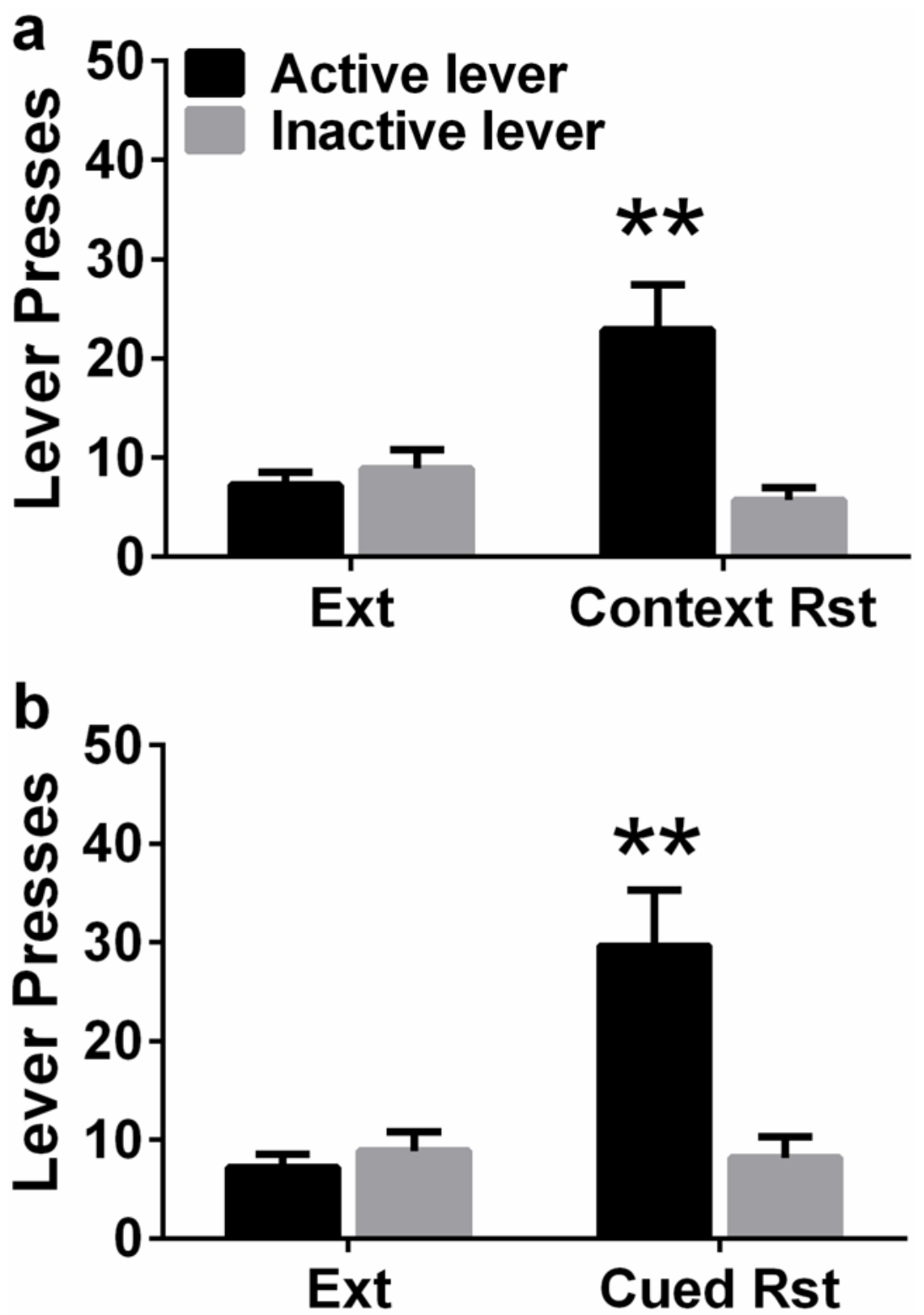

Figure 2.

Active and inactive lever responses during extinction sessions. Data shown are represented as mean +/- SEM. *P<0.05 vs. day 1 of extinction by repeated measures two way analysis of variance (ANOVA) and Student-Newman-Keuls posttests. Data shown are represented as mean +/- SEM. 
a

Bregma $-3.1 \mathrm{~mm}$

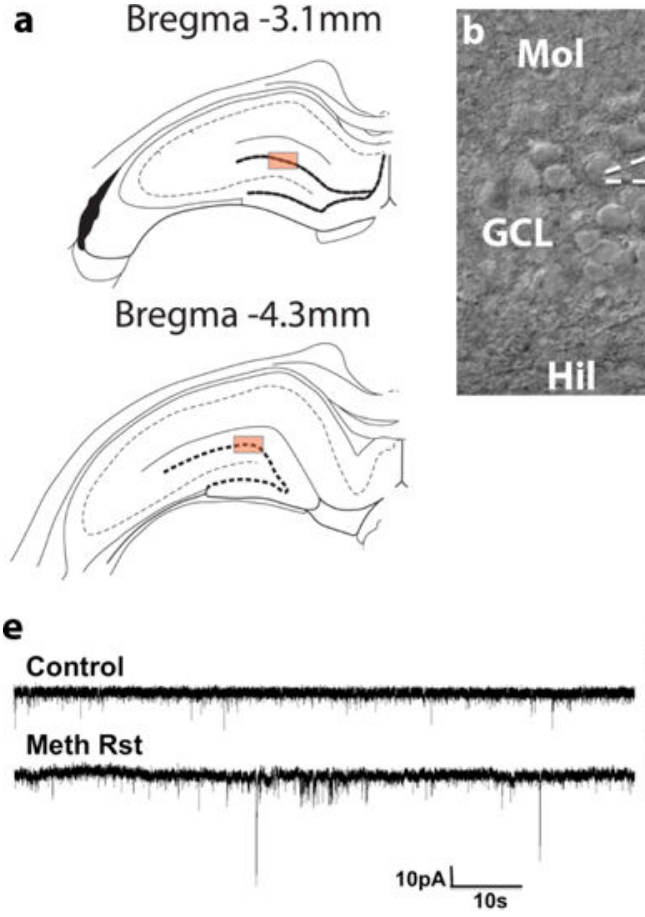

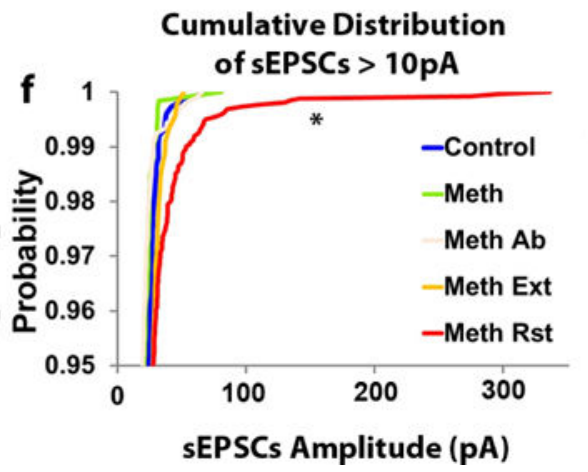
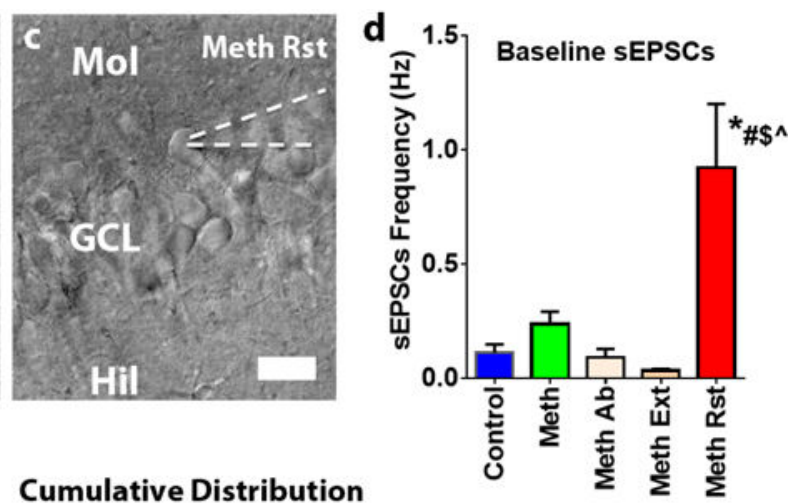

Figure 3.

Methamphetamine seeking triggered by context (a) and cues (b); reinstatement expressed as active lever presses. $\mathrm{n}=19 ;{ }^{* *} \mathrm{p}<0.01$, compared with extinction responding. Data shown are represented as mean $+/-$ SEM. 

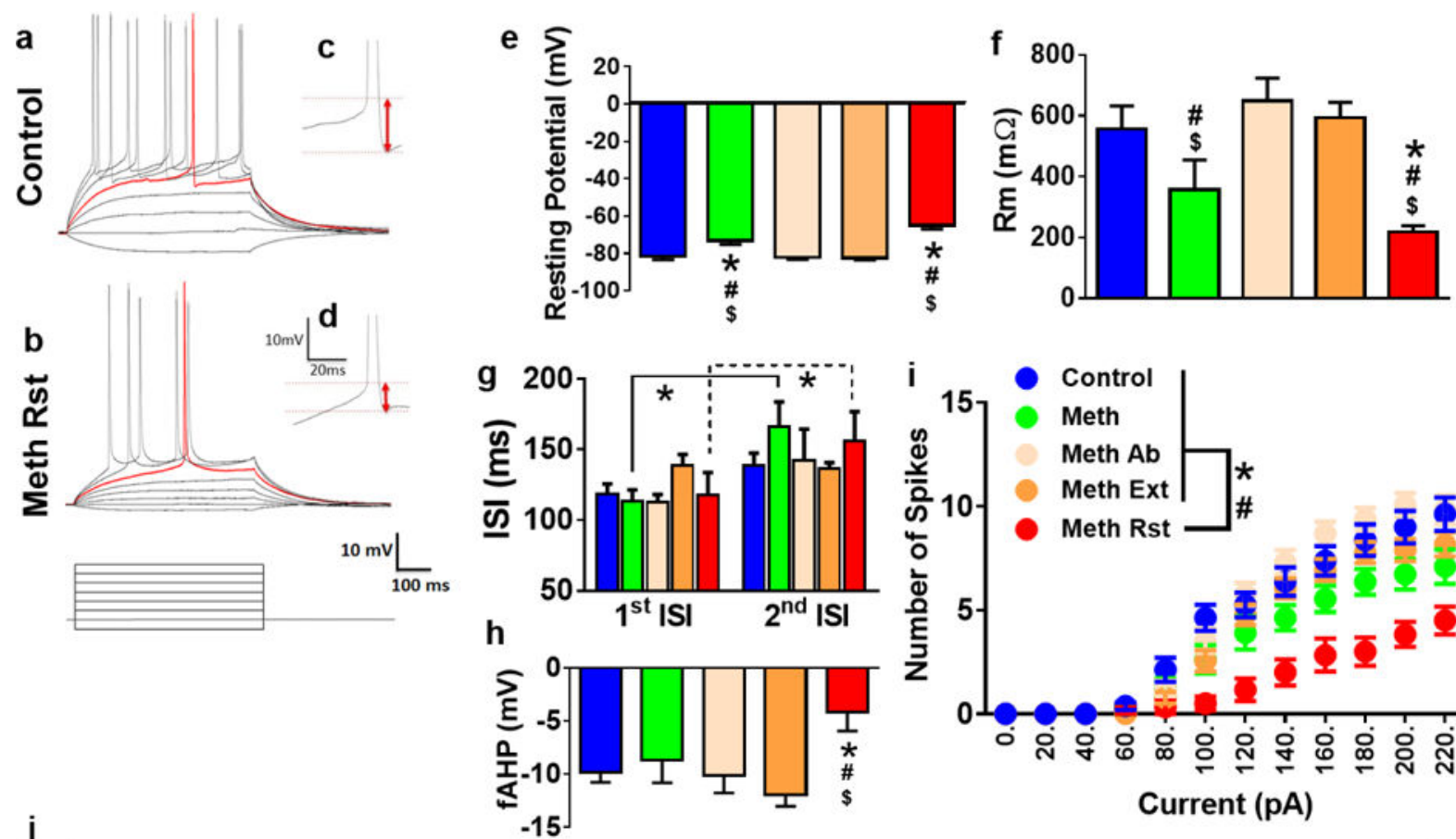

$-15$

\begin{tabular}{|l|c|c|c|c|c|}
\hline \multirow{2}{*}{ Electrophysiological properties of GCNs } \\
\cline { 2 - 6 } & Naïve Control & Meth & Meth Ab & Meth Ext & Meth Rst \\
\hline Time to peak (ms) & $256 \pm 23.4$ & $286 \pm 14.8$ & $272 \pm 20.8$ & $259 \pm 11.0$ & $228 \pm 24.5$ \\
\hline Rise slope to threshold (mV/ms) & $0.23 \pm 0.4$ & $0.14 \pm 0.1$ & $0.26 \pm 0.04$ & $0.25 \pm 0.02$ & $0.21 \pm 0.03$ \\
\hline Peak Amp (mV) & $41.1 \pm 2.8$ & $46.5 \pm 1.8$ & $48.5 \pm 1.5$ & $46.7 \pm 2.4$ & $46.2 \pm 4.8$ \\
\hline Half-width (ms) & $3.0 \pm 0.2$ & $2.8 \pm 0.1$ & $3.0 \pm 0.1$ & $3.1 \pm 0.1$ & $3.3 \pm 0.2$ \\
\hline Decay slope (mV/ms) & $-15.3 \pm 2.7$ & $-18.4 \pm 1.5$ & $-21.2 \pm 1.6$ & $-20.2 \pm 1.4$ & $-14.2 \pm 2.2$ \\
\hline sAHP (mV) & $2.0 \pm 0.4$ & $0.4 \pm 0.9$ & $2.3 \pm 0.3$ & $1.1 \pm 0.3$ & $0.4 \pm 0.5$ \\
\hline Rheobase (pA) & $71.6 \pm 3.9$ & $89.4 \pm 8.3$ & $81.2 \pm 4.0$ & $86.8 \pm 3.3$ & $121 \pm 16.5$ \\
\hline Spike threshold (mV) & $-36.6 \pm 2.1$ & $-38.4 \pm 1.9$ & $-37.4 \pm 1.0$ & $-37.0 \pm 0.7$ & $-38.9 \pm 2.9$ \\
\hline
\end{tabular}

Figure 4.

(a) Schematic representation of coronal sections used for slice recordings. Box indicates regions chosen for whole cell patch-clamp recordings. (b-c) Representative images of the granule cell layer with GCNs and indication of the patch pipette on a selected GCN. Scale bar is $25 \mu \mathrm{m}$ applies b-c. (d) Frequency of sEPSCs in Hz from GCNs from control and all other methamphetamine groups. $\mathrm{P}<0.05$ vs. reinstated group by one-way ANOVA. (e) Representative spontaneous excitatory postsynaptic currents (sEPSCs) traces in voltageclamp recording. Traces were recorded from GCNs in drug naïve (control) and reinstated (Meth Rst, methamphetamine reinstatement) rat slices. (f) Cumulative distribution of all sEPSCs above -10pA from GCNs from control and all other methamphetamine groups. $* \mathrm{P}<0.05$ vs. naïve control group by Kolmogorov-Smimov test. Data shown are represented as mean $+/-$ SEM. Number of GCNs, $n=8$ controls, $n=8$ meth (acute withdrawal), $n=14$ meth ab (methamphetamine abstinence), $\mathrm{n}=15$ meth ext (methamphetamine extinction) and $\mathrm{n}=8$ meth rst (methamphetamine reinstated). (g) Number of Fos immunoreactive cells in the $\mathrm{GCN}$ in control and reinstated rats. $\mathrm{N}=6$ controls, $\mathrm{n}=13$ reinstated rats. ${ }^{*} \mathrm{p}<0.05$ vs. controls by Unpaired $t$ test. 


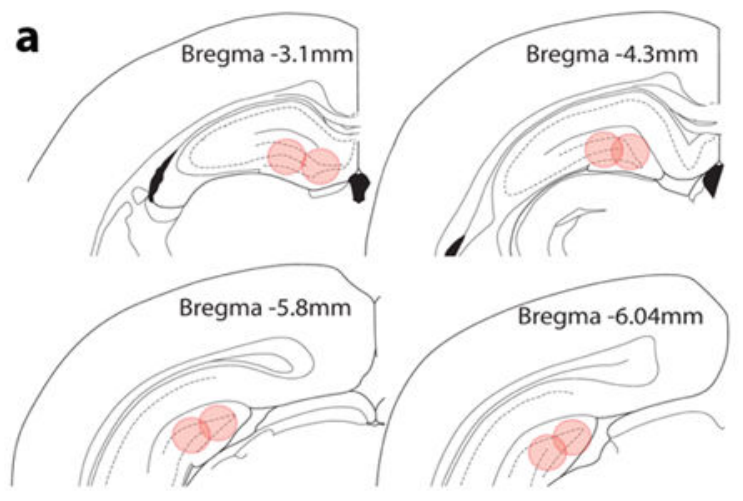

b
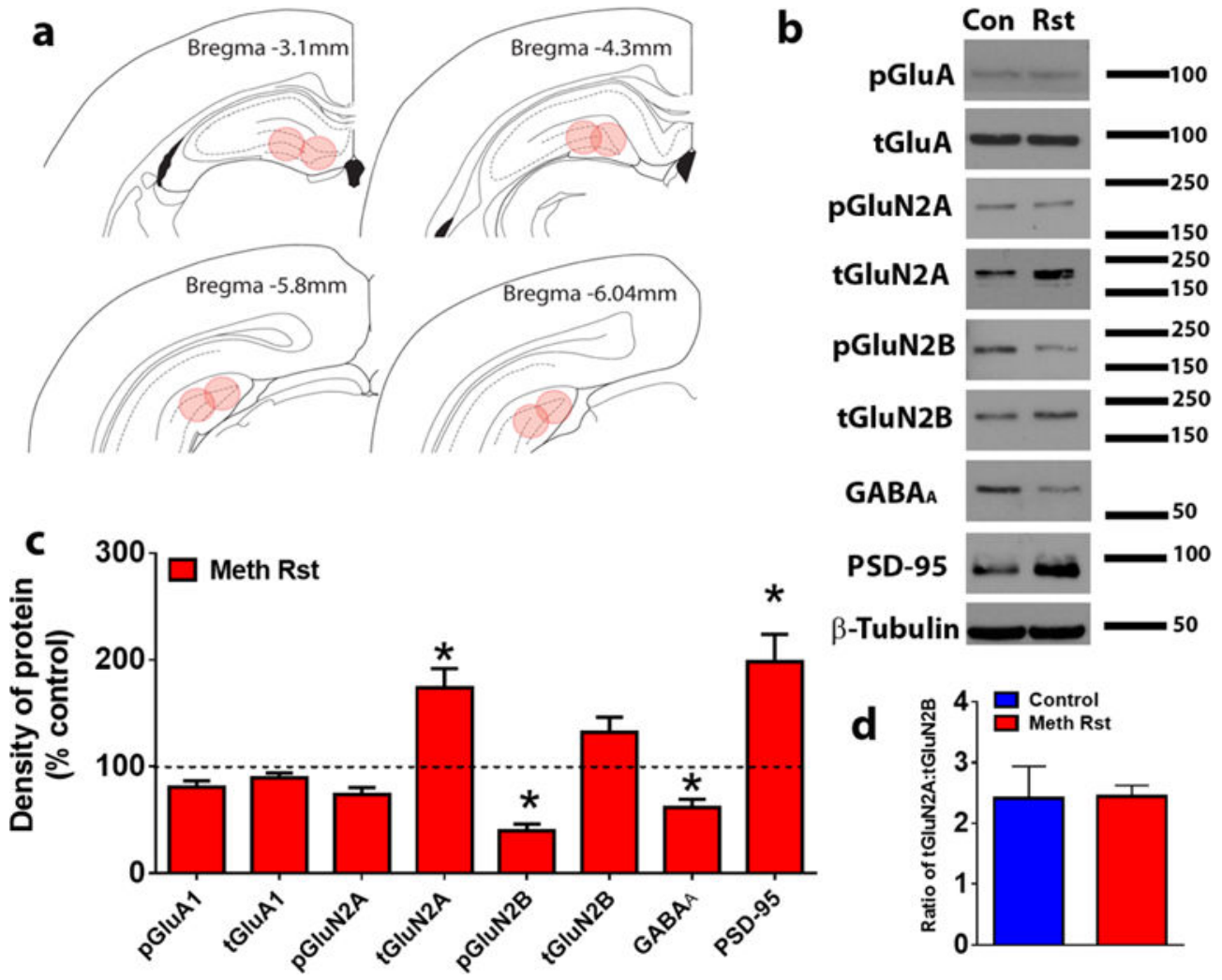

Figure 5.

(a-b). Representative traces of action potentials elicited by depolarizing current injections.

Traces were recorded from GCNs from control (a) and methamphetamine reinstated (b) rats. (c-d) Representative traces of fAHP from controls (c) and reinstated (d) rats. (e-h)

Comparison of intrinsic and active membrane properties. Analysis across all cells indicated that under baseline conditions resting potential (e), membrane resistance (f), inter-spike interval (ISI, g), fAHP (h) of GCNs showed significant difference between control and reinstated rats. (i) Graphical relationship between the number of spikes elicited by increasing current injections in current-clamp recording. (j) Electrophysiological properties of GCNs from control and all other treatment groups. ${ }^{*} \mathrm{P}<0.05$ vs. controls, $\# \mathrm{p}<0.05$ vs. Meth $\mathrm{Ab}$, $\$ \mathrm{p}<0.05$ vs. Meth Ext by ANOVA in $\mathbf{e}, \mathbf{f}, \mathbf{h} ;{ }^{*} \mathrm{P}<0.05$ vs. $1^{\text {st }}$ ISI by repeated measures ANOVA in $\mathbf{g} ;{ }^{*} \mathrm{P}<0.05$ vs. controls by repeated measures two-way ANOVA and ${ }^{\#} \mathrm{P}<0.05$ significant interaction in i. Data shown are represented as mean + /- SEM. Number of GCNs, $\mathrm{n}=7-8$ controls, $\mathrm{n}=8$ meth (acute withdrawal), $\mathrm{n}=14-16$ meth ab (methamphetamine abstinence), $\mathrm{n}=13-15$ meth ext (methamphetamine extinction) and $\mathrm{n}=6-8$ meth rst (methamphetamine reinstated). 
a

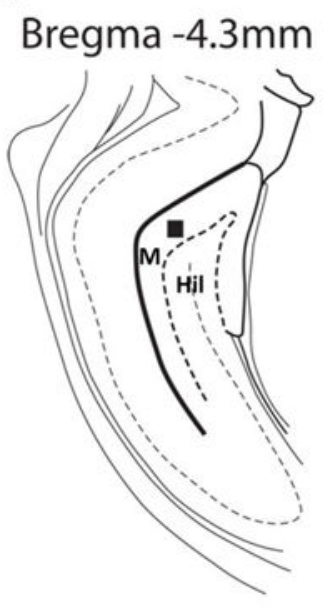

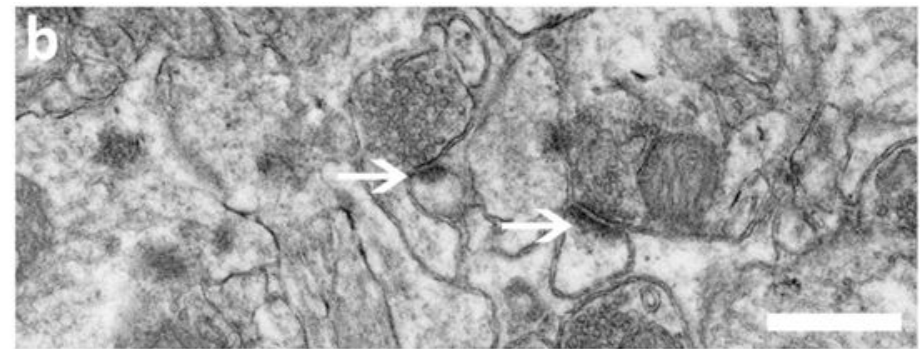

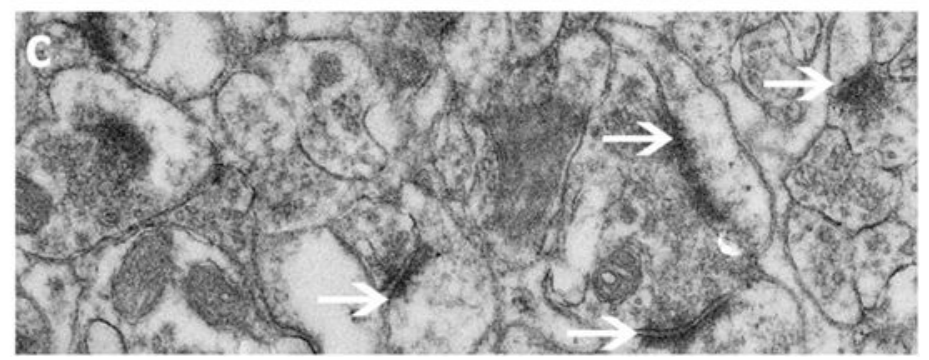

Figure 6.

(a) Schematic representation of coronal sections used for DG enriched tissue punches for Western blotting analysis. (b) Representative immunoblots of each protein measured with observed molecular weight in $\mathrm{kDa}$. Rst, reinstated rats. (c) Quantitative analysis of density of proteins shown in (b). (d) Ratio of GluN2A to GluN2B. Data shown are represented as mean $+/$ - SEM. $n=11$ controls, $n=16$ reinstated rats. $* \mathrm{P}<0.05$ vs. controls by unpaired t-test. 
a Age in days

P91

P106 -118

P119 -124

P125 -126

\begin{tabular}{|c|c|c|c|}
\hline 14 Meth sessions & & $\begin{array}{l}6 \text { extinction } \\
\text { sessions }\end{array}$ & $\begin{array}{l}2 \text { Reinstatement } \\
\text { sessions }\end{array}$ \\
\hline $\begin{array}{l}\text { Operant conditioning } \\
\text { Context A }\end{array}$ & Home cage & $\begin{array}{l}\text { Operant box } \\
\text { Context B }\end{array}$ & $\begin{array}{l}\text { Operant box } \\
\text { Context A }-/+\end{array}$ \\
\hline
\end{tabular}

Age matched controls ( Group 1)

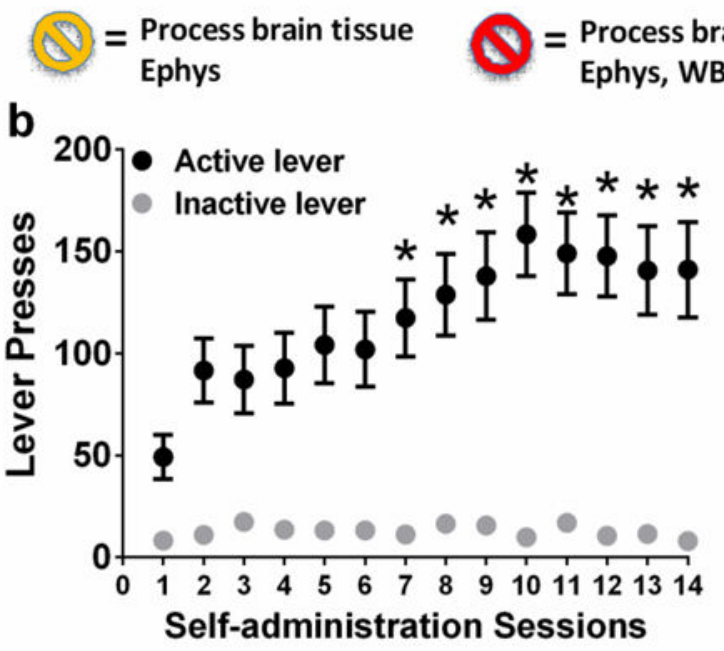

ain tissue
IHC, EM

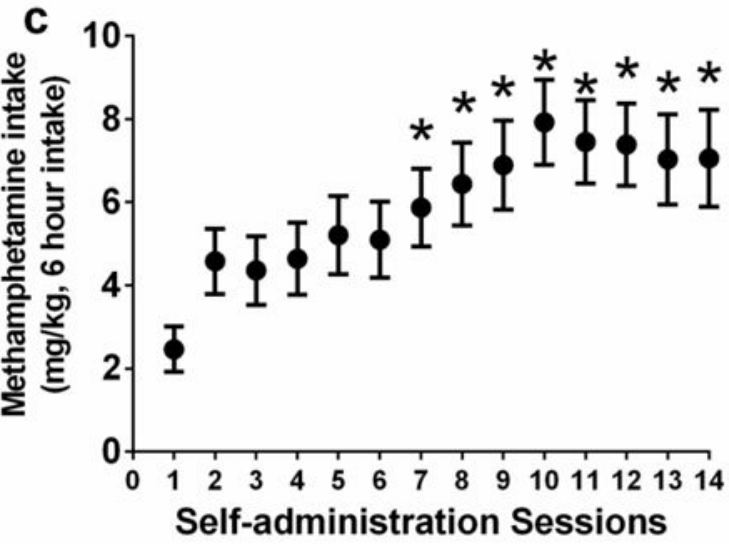

Figure 7.

(a) Schematic of a coronal section through the dorsal DG showing area chosen for electron microscopy analysis; selection area is indicated by a black square. M, molecular layer; Hil, hilus. (b-c) Ultrastructural images of presynaptic and post synaptic terminals in the molecular layer of the dorsal DG in control (b) and reinstated (c) rats. Arrow points to synaptic PSD in each panel. Scale bar in (b) is $500 \mathrm{~nm}$, applies b-c. 

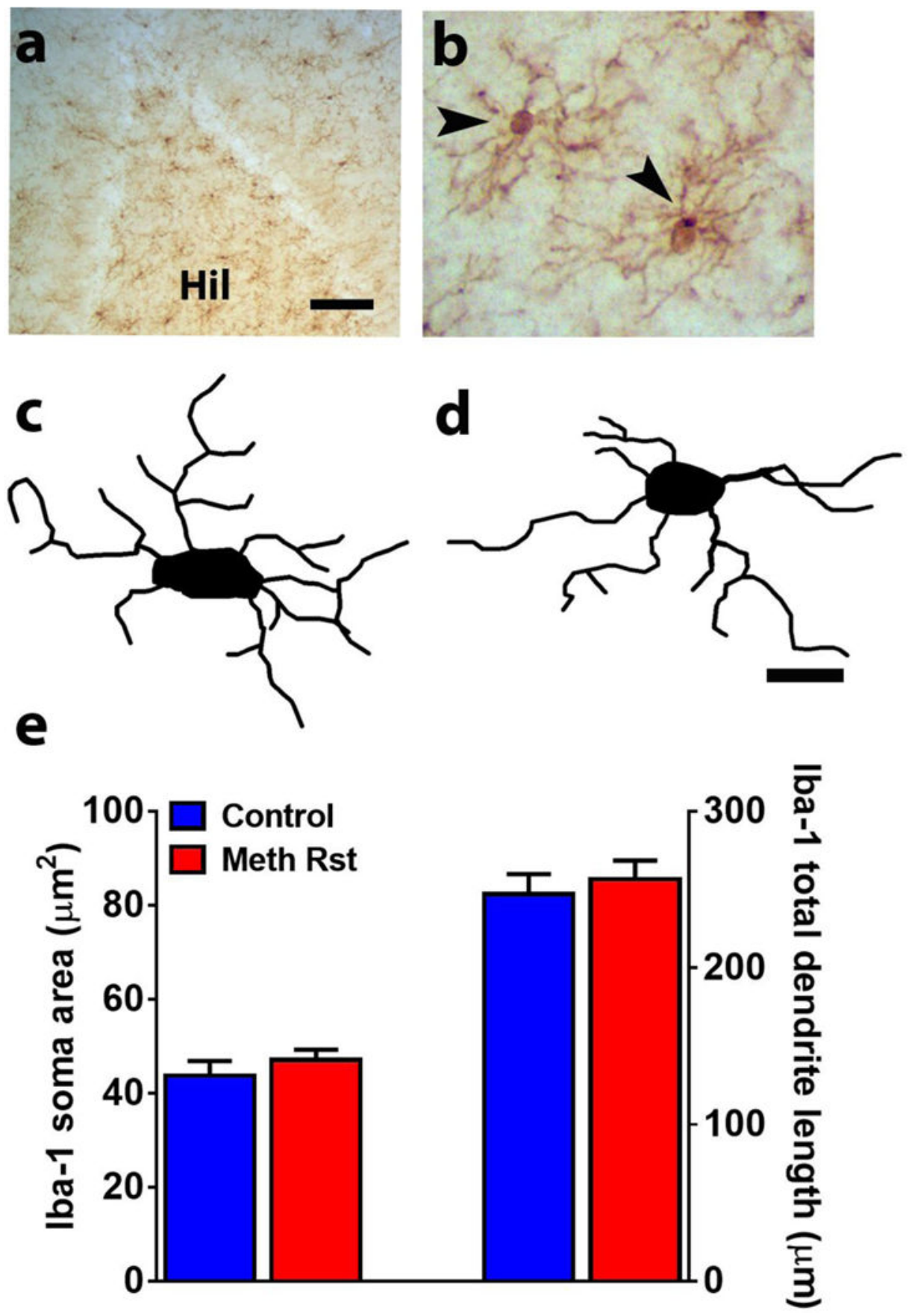

Figure 8.

(a-b) Photomicrograph of Iba-1 staining in the DG at low (a) and high (b) magnification. Hil, hilus. Scale bar in a is $100 \mathrm{um}$, in $\mathrm{b}$ is $20 \mathrm{um}$. Arrow in $\mathrm{b}$ points to an immunoreactive cell. (c-d) 3D Sholl analysis of Iba-1 cells from control (c) and reinstated (d) rats. Scale bar is 10 um for tracings. (e) Quantitative analysis of cell soma area and length of processes of Iba- 1 cells from control and reinstated rats. $n=8$ controls, $n=15$ reinstated rats. 